\title{
Fortalecimiento de la clasificación como habilidad del pensamiento hacia la competencia investigativa
}

\author{
Mauricio Uricoechea Guzmán* \\ Rosa Elena Bautista Raba** \\ Elisabeth Reyes Albañil ${ }^{* * *}$ \\ Flor Mary Umaña Buitrago *****
}

Artículo de investigación

Fecha de Recepción: 23 marzo 2018.

Fecha de Aprobación: 30 julio 2018.

\section{Resumen}

En la actualidad, nos encontramos frente a una transformación social basada en el avance del conocimiento, la tecnología, la información, la comunicación e innovación; fenómenos que dependen directamente de la investigación. Por lo anterior, es una meta en el desarrollo de los procesos educativos lograr una aproximación al trabajo investigativo en los estudiantes, promoviendo acciones transformadoras y generadoras de conocimiento. Es aquí donde las habilidades del pensamiento se convierten en las herramientas indispensables para que el estudiante adquiera, aplique y categorice los contenidos programáticos del conocimiento. A través de la experiencia docente en el aula, se evidencia que los estudiantes del curso quinto y primero de la sección primaria de la Institución Educativa Técnico Comercial Sagrado Corazón de Jesús, del municipio de Chiquinquirá, Boyacá, manifiestan: falta de interés, atención dispersa, desmotivación y apatía ante situaciones que implican la indagación de nuevos saberes. Así, esta situación sumada a los bajos niveles de rendimiento
* Universidad Pedagógica y Tecnológica de Colombia, Boyacá Colombia. mauguz1967@yahoo.es ** Institución Educativa Técnico Comercial Sagrado Corazón de Jesús, Boyacá Colombia. rosbaut24@yahoo.com *** Institución Educativa Técnico Comercial Sagrado Corazón de Jesús, Boyacá, Colombia.

lizreyes.06@hotmail.com ****Institución Educativa Técnico Comercial Sagrado Corazón de Jesús, Boyacá, Colombia.

flormarycilla@gmail.com

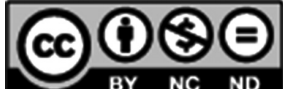


académico observados en estudiantes latinoamericanos en las pruebas del Programa Internacional para la Evaluación de estudiantes PISA (2012), y de los colombianos en las pruebas SABER del Instituto Colombiano para la Evaluación de la Educación ICFES (2016), motiva la necesidad de modificar los procesos de enseñanza y aprendizaje, y promover el desarrollo de habilidades de pensamiento para comprender y enfrentar el mundo actual con una actitud científica. En tal sentido, surge la inquietud del grupo de investigación de iniciar un aporte al Plan de Mejoramiento Institucional PMI (2015), para fortalecer la clasificación como habilidad del pensamiento en el área de ciencias naturales, la cual posibilita la relación con su entorno natural y la respuesta a las dudas que éste le sugiere al estudiante. Para tal efecto, se apropian como referentes teóricos: la teoría del desarrollo del pensamiento cuyo libro fue escrito por Piaget (1975), tomando los tipos y estadios de la clasificación según la etapa, la clasificación dentro de las habilidades de pensamiento según Amestoy de Sánchez (citada en Amaya, 2003); y la competencia investigativa como lo afirma Fonseca (s.f.). La estructura de esta investigación muestra tres etapas fundamentales: en primer orden, la aplicación de una prueba diagnóstica del nivel de desarrollo de la clasificación; luego, realiza una comparación; y finaliza, con una reflexión analítica del proceso de clasificación que trae el estudiante en el paso de preescolar al inicio de la primaria, y de igual forma mirar su avance al finalizar la misma, en el curso quinto. El producto de dicho ejercicio analítico incluye una propuesta con siete talleres de las clasificaciones de animales y trabajo fotográfico por cada taller de ejemplos de animales de la región, de esta manera, da un primer paso de indagación; y un taller más con la aplicación de un software educativo determinado por ideas propias del grupo de investigación, para incluir el uso didáctico de las TIC, el cual contiene características específicas para clasificar animales; por último, la ejecución de la prueba final que evidenciará el avance del proceso de la clasificación como habilidad del pensamiento según la comparación con la prueba diagnóstica.

Palabras clave: clasificación, habilidad, pensamiento, competencia investigativa, ciencias naturales. 


\section{Introducción}

La presente investigación es el resultado del estudio realizado en la sección primaria de la Institución Educativa Técnico Comercial "Sagrado Corazón de Jesús" del municipio de Chiquinquirá, departamento de Boyacá, a partir del análisis de necesidades dentro de la cotidianidad y la realidad docente. Así, busca la posibilidad de dar un paso al espíritu investigativo de los estudiantes, puesto que es una preocupación permanente y una tarea no cumplida dentro de análisis institucionales en el Proyecto Educativo-PEI (2014) y el Plan de Mejoramiento Institucional-PMI (2015).

Es entonces, cuando el equipo investigador busca alrededor de la competencia investigativa de los estudiantes, un componente del proceso de aprendizaje que les motive en la construcción de sus saberes, y en el estado de arte encuentra el estudio de la autora Restrepo (2007), Habilidades Investigativas en niños y niñas de 5 a 7 años de Instituciones oficiales y privadas de la ciudad de Manizales, el cual es de gran importancia para esta investigación pues aporta las pautas metodológicas para adaptar la prueba diagnóstica.

De acuerdo con lo anterior, se toma la decisión de fundamentar el marco teórico que incluye, en primer orden, el estudio de la habilidad de la clasificación que aborda Piaget (1975) con la Teoría del Desarrollo del Pensamiento; seguidamente el análisis que al respecto realiza Amestoy (1995). Y así, dar paso a una aproximación del fortalecimiento de la habilidad investigativa de los estudiantes, con los aportes de Fonseca (s.f.), para de esta manera motivar el espíritu investigativo por medio de la habilidad de la clasificación, no solo como parte del proceso mental de aprendizaje, sino también como experiencia constructora de saberes.

Por lo tanto, el paradigma del proyecto es interpretativo (Pérez \& Serrano citados en Martínez, 2013), ya que el investigador tiene una posición participativa, y la investigación pretende la descripción de situaciones específicas (personas y comunidades).

El enfoque de la investigación es mixto. Conforme con Creswell (citado en Pereira, 2011), permite integrar en un mismo estudio, metodologías cuantitativas y cualitativas, con el propósito de comprender en forma completa el objeto de estudio. Así, la aceptación del paradigma mixto permite tener una perspectiva más precisa de un fenómeno de la clasificación.

Por lo anterior, el tipo de investigación es Investigación-Acción Educativa, que, según Elliott (citado en Murillo, 2010), busca reflexionar sobre las acciones de los estudiantes para modificar la situación una vez que se logre una comprensión más profunda del problema; en este caso, busca caracterizar el nivel de clasificación como habilidad investigativa, para dar luego un aporte de mejoramiento a las
La presente investigación es el resultado del estudio realizado en la sección primaria de la Institución Educativa Técnico Comercial "Sagrado Corazón de Jesús” del municipio de Chiquinquirá, departamento de Boyacá, a partir del análisis de necesidades dentro de la cotidianidad y la realidad docente. 
debilidades que arroje el análisis de resultados del diagnóstico.

En ese orden, la investigación presenta tres momentos fundamentales que responden a los objetivos propuestos: en primer término, diagnosticar mediante una prueba el nivel de clasificación como habilidad del pensamiento hacia la competencia investigativa en el área de ciencias naturales, con el nivel inicial y final de educación básica primaria. Seguidamente, realizar la comparación de este proceso, en los dos niveles educativos, para reflexionar alrededor de diversas posibilidades de aporte al mejoramiento, tanto de la habilidad de la clasificación como también de la competencia investigativa de los estudiantes.

Finalmente, se diseña, aplica y evalúa una propuesta compuesta por siete talleres creados por el equipo investigador, teniendo en cuenta el taller como alternativa de renovación pedagógica propuesta por Ander Egg (1999), los cuales incluyen actividades de clasificaciones de animales, trabajos artísticos, exposiciones y álbum fotográfico; y el último consta de un software lúdico teniendo en cuenta el auge actual de las TIC como estrategia metodológica de aprendizaje. Una experiencia enriquecedora no solo para la construcción y reafirmación de aprendizajes del área de ciencias naturales, el fortalecimiento de la habilidad de la clasificación con la temática de los animales y una aproximación investigativa de los estudiantes, sino también un encuentro en familia con la naturaleza, registro fotográfico y despliegue de creaciones artísticas.

Para dar cierre a la investigación, se realiza una prueba final que permite evidenciar junto con la diagnóstica, los aportes de la propuesta, tanto a nivel de clasificación como de aproximación al proceso de investigación de los estudiantes. Además, reflexionar alrededor de la experiencia integral desde el rol personal, docente y como participante del equipo investigador, y así ver las posibilidades de la extensión de la propuesta para otras áreas y grados.

\section{Marco teórico}

\section{Estado del arte}

Para la presente investigación, es determinante conocer algunos trabajos que versan sobre la misma temática a nivel internacional, nacional, regional y local, por lo cual se ha realizado una exhaustiva búsqueda y se determinó que los siguientes trabajos aportan ostensiblemente a nuestro propósito.

En primer orden, a nivel internacional, a mitad de la década de los 70, Dianelkys Martínez Rodríguez y Dora Lilia Márquez Delgado de la Universidad de Pinar del Río "Hermanos Saíz Montes de Oca”, presentan la formación y el desarrollo de habilidades investigativas. A nivel nacional, Colciencias y el Ministerio de Educación Nacional, a partir de la década de los 80, establecieron programas con el fin de incentivar procesos investigativos en los estudiantes, desde "Cuclí-Cuclí" (1989) hasta "Ondas" (2001), entre otros. 
También, está el estudio de la autora Francia Restrepo de Mejía, Habilidades Investigativas en niños y niñas de 5 a 7 años de instituciones oficiales y privadas de la ciudad de Manizales, el cual es de gran importancia para esta investigación, pues aporta las pautas metodológicas para adaptar la prueba diagnóstica.

\section{Teorías del conocimiento}

Así mismo, a continuación se presentarán las teorías que nos aportan a la investigación:

\section{La clasificación dentro de} la Teoría del Desarrollo del Pensamiento de Piaget

Las personas aprenden a clasificar objetos a partir de sus semejanzas y a establecer relaciones de pertenencia entre los objetos y los conjuntos en que están incluidos. Según Piaget (1975), la clasificación inicia en el periodo preoperacional (2-7 años), pasa por el periodo de operaciones concretas (711 años) y se consolida en el periodo de operaciones formales (11-15 años); posteriormente, es utilizada en las diferentes acciones de su vida diaria donde use sistemas clasificatorios.

Sistemas clasificatorios. Piaget (1975) distingue tres tipos de contenidos básicos: la clasificación simple, la clasificación múltiple y la inclusión de clases. La primera consiste en agrupar objetos con respecto a una sola dimensión o criterio; la segunda, en clasificar objetos simultáneamente con respecto a dos o más dimensiones o criterios; y, la última, es una relación binaria entre clases que puede definirse tanto por comprensión como por extensión.

\section{Estadios de la Génesis de la clasificación. Piaget (1975) establece} tres estadios en la clasificación que hacen parte del pensamiento del niño.

Primer estadio colecciones figurales. Una colección figural es el agrupamiento de los elementos según configuraciones espaciales, que un niño ubicado en el estadio preconceptual realiza teniendo en cuenta la extensión, o sea la cantidad de elementos presentes o la comprensión indistintamente. Estas colecciones se realizan mediante relaciones de semejanza y diferencia sucesivas en el tiempo por asimilación sucesiva (no hay simultaneidad).

Segundo estadio colecciones no figurales. Son agregados fundados sobre semejanzas, yuxtapuestos sin estar incluidos en clases más generales. El niño toma uno (1) o dos (2) elementos, y luego piensa dónde los agrupa. Solo realiza ciertas anticipaciones y regulaciones por tanteo.

Tercer estadio clasificación. Según Piaget, lo que permite el descentramiento que posibilita el pasaje del estadio preoperatorio al operatorio concreto, es la noción de reversibilidad. Por lo tanto, el concepto de reversibilidad, que es una capacidad de razonar, está asociado a la noción temporal de simultaneidad. Esto quiere decir que el sujeto es capaz de tener en cuenta dos variables, pero de manera simultánea y no sucesiva, como en el estadio anterior.
Las personas aprenden a clasificar objetos a partir de sus semejanzas y a establecer relaciones de pertenencia entre los objetos y los conjuntos en que están incluidos. 
La clasificación como habilidad de pensamiento según Margarita Amestoy de Sánchez. La clasificación es, según Amestoy (1995), un proceso mental que permite agrupar personas, objetos, eventos o situaciones con base en sus semejanzas y diferencias; es una operación epistemológica fundamental. Antes de clasificar, el individuo cumple las siguientes habilidades de pensamiento: observación y descripción, inclusión, exclusión, intersección, diferencias, semejanzas, comparación y relación, características esenciales, definición de conceptos, cambios y secuencias, transformaciones, clasificación jerárquica, variables ordenables. De esta forma, llega a la clasificación, la cual le permite identificar personas, objetos, eventos o situaciones que jamás se han visto, identificar o definir conceptos y plantear hipótesis, también reconoce efectuar dos tipos de operaciones mentales: agrupar conjuntos de personas, objetos, eventos o situaciones en categorías, denominadas clases, y establecer categorías conceptuales.

La competencia investigativa. Según Fonseca (s.f.), las competencias científicas investigativas se asumen comola capacidad del sujeto de construir explicaciones y comprensiones de la naturaleza, a partir de la indagación, la experimentación y la contrastación teórica.

Ander Egg y el taller: una alternativa de renovación pedagógica. Para Ander Egg (1999), el taller indica un lugar donde hay trabajo y transformación, una forma de aprender y enseñar. Así como también es un ámbito de reflexión y de acción en el que se pretende superar la separación que existe entre la teoría y la práctica, entre el conocimiento y el trabajo, y entre la educación y la vida, que se da en todos los niveles de la educación desde la enseñanza primaria hasta la universitaria, teniendo en cuenta las diversas experiencias que esto implica.

\section{Metodología}

Paradigma. Según Pérez Serrano (citado en Martínez, 2013). El paradigma es interpretativo, pues asume que el investigador debe tener una posición participativa, y que la investigación requiere de la descripción de situaciones específicas (personas y comunidades).

Para Pérez y Serrano (citado en Ricoy, 2006), las características más importantes de este paradigma son:

- La teoría constituye una reflexión en y desde la praxis, conformando la realidad de hechos observables y externos, por significados e interpretaciones elaboradas del propio sujeto, a través de una interacción con los demás dentro de la globalidad de un contexto determinado. Se hace énfasis en la comprensión de los procesos desde las propias creencias, valores y reflexiones. El objetivo de la investigación es la construcción de teorías prácticas, configuradas desde la práctica. Utiliza la metodología etnográfica y suele trabajar con datos cualitativos. 
- Intenta comprender la realidad, considera que el conocimiento no es neutral. Es relativo a los significados de los sujetos en interacción mutua y tiene pleno sentido en la cultura y en las peculiaridades de la cotidianidad del fenómeno educativo. En este sentido, tiene lógica remontarnos al pasado para comprender $\mathrm{y}$ afrontar mejor el presente.

- Describir el hecho en el que se desarrolla el acontecimiento, en él que el uso de la metodología cualitativa permite hacer una rigurosa descripción contextual de estas situaciones que posibilitan la intersubjetividad en la captación de la realidad, a través de una recogida sistemática de los datos que admite el análisis descriptivo. Se apuesta por la pluralidad de métodos y la utilización de estrategias de investigación específicas y propias de la condición humana. (p.p.16-17)

Enfoque. De acuerdo con Creswell (citado en Pereira, 2011), el enfoque de la investigación es mixto puesto que permite integrar en un mismo estudio, metodologías cuantitativas y cualitativas, con el propósito de comprender en forma completa el objeto de estudio. Así, permite tener una perspectiva más precisa de un fenómeno dado, puede conocerse tanto la frecuencia, amplitud y magnitud de un fenómeno, como su profundidad y complejidad.

Dentro de este enfoque mixto, el carácter cualitativo está de acuerdo con Gregorio Rodríguez Gómez (1996), pues refiere sucesos complejos que tratan de ser descritos en su totalidad, en su medio natural, en este caso en el contexto del aprendizaje. Para el presente estudio, los investigadores cualitativos son los docentes, quienes estudian la realidad en el aula y a través de la cotidianidad con los estudiantes, tienen como reto la permanente búsqueda del mejoramiento gradual de saberes; esta realidad permite aplicar la técnica de la observación y el registro en diario de campo como instrumento de investigación.

De otra parte, en el análisis de resultados adopta un manejo cuantitativo de los datos de acuerdo con Pita, F. y Pértegas, D. (2002), ya que "trata de determinar la fuerza de asociación o correlación entre variables, la generalización y objetivación de los resultados a través de una muestra para hacer inferencia a una población de la cual toda muestra procede" (p.1). En este caso, se realiza mediante tablas de datos numéricos del nivel de desempeño de acuerdo con la escala del sistema de evaluación institucional; también en los consolidados porcentuales y la representación de los mismos en gráficas.

Tipo. El tipo de investigación es Investigación-Acción Educativa; teniendo en cuenta que Elliott (citado en Murillo, 2010), la entiende como una reflexión sobre las acciones humanas y las situaciones sociales vividas por el profesorado que tiene como objetivo ampliar la comprensión de los docentes de sus problemas prácticos. Las acciones van encaminadas a modificar la situación 
una vez que se logre una comprensión más profunda de los problemas. (p.4). En este caso se busca caracterizar el nivel de clasificación como habilidad investigativa, para dar luego un aporte de mejoramiento a las debilidades que arroje el análisis de resultados del diagnóstico.

Fase I. Diagnóstico

En primer término, en la fase I diagnóstico, Espinoza (citado en Robles, 2014) señala que es una fase que inicia el proceso de la programación y es el punto de partida para formular el proyecto. Para tal fin, es necesario realizar un muestreo de tipo intencional o por conveniencia ( McMillan y Schumacher, 2001), donde las investigadoras seleccionan los elementos que a su juicio son representativos, están disponibles y son accesibles para la investigación, lo que exige un conocimiento previo de la población que se investiga, en este caso, la primera variable es el hecho de ser directoras de los cursos en estudio; y el segundo parámetro tiene como base la experiencia docente de las profesoras, estableciendo gran importancia del curso primero como nivel inicial y el grado quinto como nivel final del nivel de educación básica primaria.

En este caso, la población está compuesta por 554 estudiantes de básica primaria de la sede central; como muestra, los niños del grado primero cuatro, un total de 33 estudiantes (17 niñas y 16 niños), entre los 6 y 7 años. También se incluyen los 35 estudiantes del grado quinto dos, con 22 niñas y 13 niños (3 niños de inclusión), con edades entre 9 y 11 años. Los estudiantes tienen como características comunes el nivel socioeconómico entre 1 y 2 , además con gran porcentaje de familias disfuncionales.

Las tablas 1 y 2 presentan la caracterización de la población, de acuerdo con los dos cursos, pero, por razones del tipo de escrito, solo se presentará la tabla con el diez por ciento del total de los niños de cada curso.

Tabla 1

Caracterización de la población del curso primero cuatro

\begin{tabular}{ccccccc}
\hline $\begin{array}{c}\text { NÚMERO DE } \\
\text { ESTUDIANTE }\end{array}$ & SEXO & CURSO & CÓDIGO & EDAD & $\begin{array}{c}\text { ESTRATO } \\
\text { SOCIOECONÓMICO }\end{array}$ & TIPO DE FAMILIA \\
\hline 1 & $\mathrm{M}$ & $\mathrm{C} 1$ & EC 1-1 & 6 & 1 & EXTENDIDA \\
2 & $\mathrm{M}$ & $\mathrm{C} 1$ & EC 1-2 & 5 & 2 & EXTENDIDA \\
3 & $\mathrm{M}$ & $\mathrm{C} 1$ & $\mathrm{EC} 1-3$ & 6 & 1 & EXTENDIDA \\
4 & $\mathrm{~F}$ & $\mathrm{C} 1$ & EC 14 & 6 & 2 & MONOPARENTAL \\
\hline
\end{tabular}




\section{Tabla 2}

Caracterización de la población del curso quinto dos

\begin{tabular}{ccccccc}
\hline $\begin{array}{c}\text { NÚMERO DE } \\
\text { ESTUDIANTE }\end{array}$ & SEXO & CURSO & CÓDIGO & EDAD & $\begin{array}{c}\text { ESTRATO } \\
\text { SOCIOECONÓMICO }\end{array}$ & TIPO DE FAMILIA \\
\hline 1 & F & C2 & EC 2-1 & 9 & 1 & MONOPARENTAL \\
2 & F & C2 & EC 2-2 & 9 & 2 & MONOPARENTAL \\
3 & M & C2 & EC 2-3 & 10 & 2 & NUCLEAR \\
4 & M & C2 & EC 24 & 9 & 2 & NUCLEAR \\
\hline
\end{tabular}

Fuente: elaboración propia.

Así, para cumplir con el primer objetivo específico, se utiliza técnicas de recolección de la información de la observación directa Marshall y Rossman (citado en Kawulich, 2005), y como instrumento el diario de campo según Bonilla y Rodríguez (citado en Martínez, 2007) seguidamente, la evaluación diagnóstica a través de una prueba inicial.

También, se adapta una prueba diagnóstica, a través de la cual se puede saber cuál es el estado cognoscitivo y actitudinal de los estudiantes De acuerdo con Brenes (2006) 'La evaluación diagnóstica es el conjunto de técnicas y procedimientos evaluativos que se aplican antes y durante el desarrollo del proceso de instrucción" (p. 27).

Según, Pérez \& García (citados en Osores, 2014), la evaluación precisará del diagnóstico para la realización de pronósticos que permitan una actuación preventiva y que faciliten los juicios de valor de referencia personalizada, además, para personalizar el proceso educativo con objetivos adecuados de nivel y de campo, las técnicas de motivación, las actividades o la metodología. El diagnóstico será, así mismo, un momento clave en todas las situaciones de recuperación, e imprescindible en las de fracaso reiterado que exige un estudio de casos. (parr.4)

En este caso, "Juego de las Veinte preguntas” (Mosher \& Hornsby, 1980) (Rebeca Puche, 2000). Banco de Pruebas del Grupo Cognitiv@- Universidad del Valle - Cali - Colombia (citados en Restrepo, 2007). Adaptación realizada por el equipo de investigación y avalada por el doctor Javier Zambrano, profesor de investigación; y el magíster Mauricio Uricoechea, asesor de tesis. En la figura 1 se observa el diseño, muestra y evidencia de la prueba diagnóstica, del curso primero (a la izquierda) y del quinto (a la derecha). 
Figura 1. Prueba diagnóstica curso primero cuatro y curso quinto dos.

\section{PRUJBA DIAGNÓSTICA}
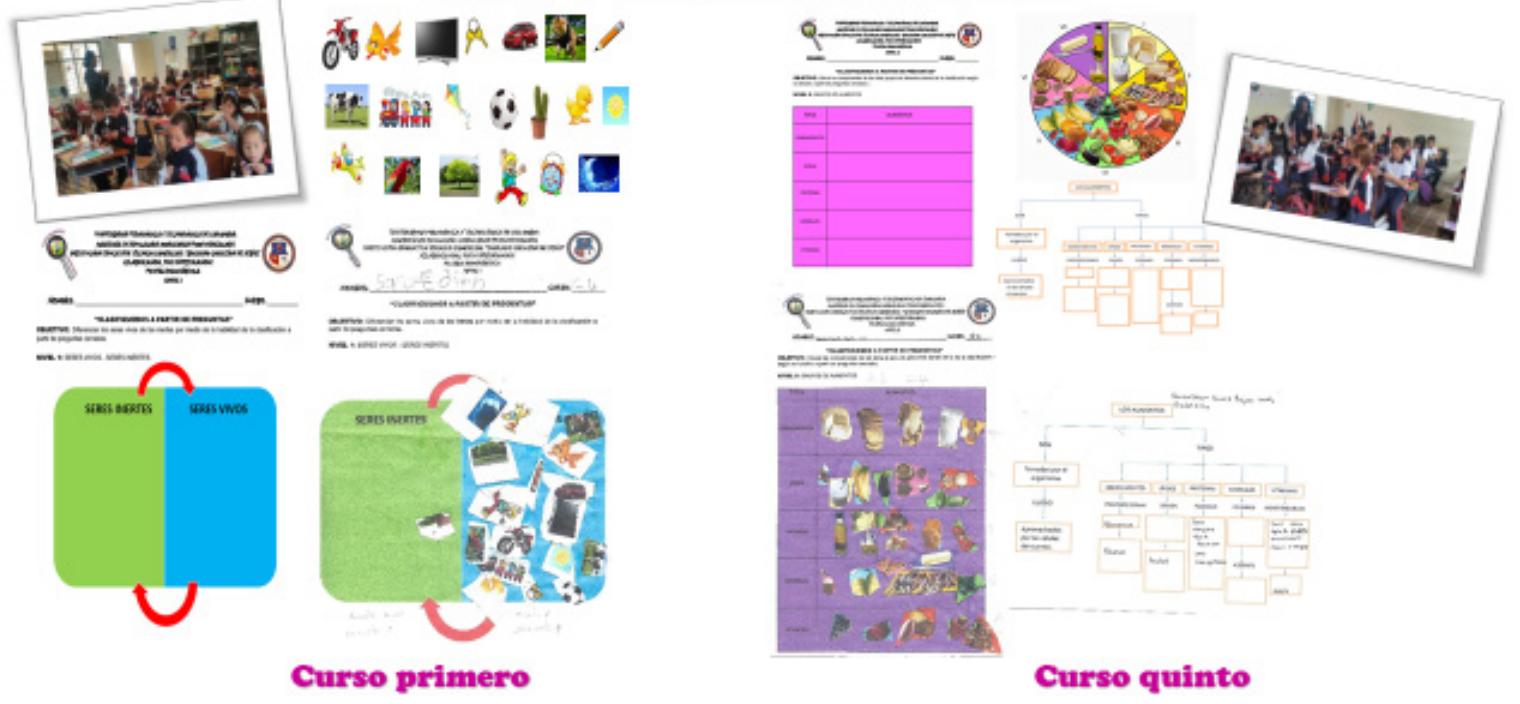

Fase II. Evaluación de la prueba diagnóstica

En la fase II, evaluación y reflexión de la prueba diagnóstica, se elabora una matriz de evaluación de los resultados, la cual permite evidenciar el desempeño de cada estudiante, teniendo en cuenta el número de aciertos en la clasificación de las imágenes, según la escala de valoración del Sistema Institucional de Evaluación de Estudiantes (SIEE).
En primer orden, el análisis cualitativo se realiza mediante la técnica de observación con el diario de campo. En la figura 2, se encuentran las categorías con el código y subcategorías, que el equipo investigador establece para el conteo y análisis de datos cualitativos; $y$ un modelo de registro de observación.

\begin{tabular}{|c|c|c|}
\hline CATEGORÍAS & CÓDIGO & SUBCATEGORÍAS \\
\hline \multicolumn{3}{|c|}{ GENERALES } \\
\hline ACEPTACIÓN & $\mathrm{AC}$ & $\begin{array}{ll}\text { - } & \text { Agrado } \\
\text { - } & \text { Curiosidad }\end{array}$ \\
\hline PARTICIPACIÓN & PT & $\begin{array}{ll} & \text { Dinamismo } \\
\text { - } & \text { Dedicación } \\
\end{array}$ \\
\hline ATENCIÓN & AT & $\begin{array}{ll}\text { - } & \text { Concentración } \\
\text { - } & \text { Disciplina }\end{array}$ \\
\hline \multicolumn{3}{|c|}{ ESPECÍFICAS } \\
\hline $\begin{array}{l}\text { TIPO DE CLASIFICACIÓN } \\
\text { Piaget (1975) }\end{array}$ & $\mathrm{TC}$ & $\begin{array}{ll}- & \text { Simple } \\
- & \text { Múltiple } \\
- & \text { Inclusión de clases } \\
\end{array}$ \\
\hline $\begin{array}{c}\text { ESTADIO } \\
\text { Piaget (1975) }\end{array}$ & EST & $\begin{array}{ll}- & \text { Primer estadio colecciones figurales } \\
- & \text { Segundo estadio colecciones no figurales } \\
- & \text { Tercer estadio clasificación } \\
\end{array}$ \\
\hline $\begin{array}{c}\text { HABILIDAD DEL PENSAMIENTO } \\
\text { Amestoy (1991) }\end{array}$ & HP & $\begin{array}{ll}- & \text { Agrupa conjuntos } \\
- & \text { Establece categorías conceptuales }\end{array}$ \\
\hline
\end{tabular}

Figura 2. Modelo de análisis cualitativo del diario de campo de la prueba diagnóstica 
Por otra parte, en cuanto a los datos cuantitativos, se consolidan los resultados obtenidos en la prueba diagnóstica tanto del curso primero cuatro como de quinto dos, ubicando como criterios evaluativos, el nivel de desempeño de acuerdo al SIEE (2015); el nivel y estadio de clasificación, según Piaget (1975) y el proceso de clasificación como habilidad del pensamiento, siguiendo a Amestoy (1995). Las tablas 3 y 4, muestran el resultado individual de los estudiantes que conforman la población en estudio.

Tabla 3

Consolidado de resultados de la prueba diagnóstica del curso primero cuatro

\begin{tabular}{|c|c|c|c|c|c|c|c|c|}
\hline Estudiante & $\begin{array}{c}\text { ETAPA DEL } \\
\text { PENAAMIENTO } \\
\text { (PIAGET) }\end{array}$ & $\begin{array}{c}\text { ACIER } \\
\text { TOS }\end{array}$ & DESACIERTOS & NOTA & $\begin{array}{c}\text { NIVEL DE } \\
\text { DESEMPEÑO }\end{array}$ & $\begin{array}{c}\text { TIPO DE } \\
\begin{array}{c}\text { CLASIFICACIÓN } \\
\text { (PIAGET) }\end{array}\end{array}$ & $\begin{array}{l}\text { ESTADIO } \\
\text { (PIAGET) }\end{array}$ & $\begin{array}{l}\text { HABILIDAD DEL } \\
\text { PENSAMIENTO } \\
\text { (MARGARIT } \\
\text { AMESTOY DE S.) }\end{array}$ \\
\hline EC 1-1 & Preoperacional & 13 & 7 & 3.25 & BÀSICO & SIMPLE & $\begin{array}{l}\text { PRIMER ESTADIO } \\
\text { Colecciones figurales }\end{array}$ & Agrupa conjuntos \\
\hline EC 1-2 & Preoperacional & 12 & 8 & 3 & BÀSICO & SIMPLE & $\begin{array}{l}\text { PRIMER ESTADIO } \\
\text { Colecciones figurales }\end{array}$ & Agrupa conjuntos \\
\hline EC 1-3 & Preoperacional & 10 & 10 & 2.5 & BAJO & SIMPLE & $\begin{array}{l}\text { PRIMER ESTADIO } \\
\text { Colecciones figurales }\end{array}$ & Agrupa conjuntos \\
\hline EC 1-4 & Preoperacional & 12 & 8 & 3 & BÀSICO & SIMPLE & $\begin{array}{l}\text { PRIMER ESTADIO } \\
\text { Colecciones figurales }\end{array}$ & Agrupa conjuntos \\
\hline EC $1-5$ & Preoperacional & 9 & 11 & 2.25 & BAJO & SIMPLE & $\begin{array}{l}\text { PRIMER ESTADIO } \\
\text { Colecciones figurales }\end{array}$ & Agrupa conjuntos \\
\hline EC 1-6 & Preoperacional & 12 & 8 & 3 & BÀSICO & SIMPLE & $\begin{array}{l}\text { PRIMER ESTADIO } \\
\text { Colecciones figurales }\end{array}$ & Agrupa conjuntos \\
\hline EC 1-7 & Preoperacional & 9 & 11 & 2.25 & BAJO & SIMPLE & $\begin{array}{l}\text { PRIMER ESTADIO } \\
\text { Colecciones figurales }\end{array}$ & Agrupa conjuntos \\
\hline EC 1-8 & Preoperacional & 9 & 11 & 2.25 & BAJO & SIMPLE & $\begin{array}{l}\text { PRIMER ESTADIO } \\
\text { Colecciones figurales }\end{array}$ & Agrupa conjuntos \\
\hline EC 1-9 & Preoperacional & 11 & 9 & 2.75 & BAJO & SIMPLE & $\begin{array}{l}\text { PRIMER ESTADIO } \\
\text { Colecciones figurales }\end{array}$ & Agrupa conjuntos \\
\hline EC $1-10$ & Preoperacional & 16 & 4 & 4 & ALTO & MÚLTIPLE & $\begin{array}{l}\text { SEGUNDO ESTADIO } \\
\text { Colecciones no } \\
\text { figurales }\end{array}$ & $\begin{array}{l}\text { Establece categorías } \\
\text { conceptuales }\end{array}$ \\
\hline EC 1-11 & Preoperacional & 12 & 8 & 3 & BÀSICO & SIMPLE & $\begin{array}{l}\text { PRIMER ESTADIO } \\
\text { Colecciones figurales }\end{array}$ & Agrupa conjuntos \\
\hline EC 1-12 & Preoperacional & 8 & 12 & 2 & BAJO & SIMPLE & $\begin{array}{l}\text { PRIMER ESTADIO } \\
\text { Colecciones figurales }\end{array}$ & Agrupa conjuntos \\
\hline EC 1-13 & Preoperacional & 9 & 11 & 2.25 & BAJO & SIMPLE & $\begin{array}{l}\text { PRIMER ESTADIO } \\
\text { Colecciones figurales }\end{array}$ & Agrupa conjuntos \\
\hline EC $1-14$ & Preoperacional & 10 & 10 & 2.5 & BAJO & SIMPLE & $\begin{array}{l}\text { PRIMER ESTADIO } \\
\text { Colecciones figurales }\end{array}$ & Agrupa conjuntos \\
\hline EC $1-15$ & Preoperacional & 8 & 12 & 2 & BAJO & SIMPLE & $\begin{array}{l}\text { PRIMER ESTADIO } \\
\text { Colecciones figurales }\end{array}$ & Agrupa conjuntos \\
\hline EC 1-16 & Preoperacional & 9 & 11 & 2.25 & BAJO & SIMPLE & $\begin{array}{l}\text { PRIMER ESTADIO } \\
\text { Colecciones figurales }\end{array}$ & Agrupa conjuntos \\
\hline EC $1-17$ & Preoperacional & 10 & 10 & 2.5 & BAJO & SIMPLE & $\begin{array}{l}\text { PRIMER ESTADIO } \\
\text { Colecciones figurales }\end{array}$ & Agrupa conjuntos \\
\hline EC 1-18 & Preoperacional & 9 & 11 & 2.25 & BAJO & SIMPLE & $\begin{array}{l}\text { PRIMER ESTADIO } \\
\text { Colecciones figurales }\end{array}$ & Agrupa conjuntos \\
\hline EC 1-19 & Preoperacional & 9 & 11 & 2.25 & BAJO & SIMPLE & $\begin{array}{l}\text { PRIMER ESTADIO } \\
\text { Colecciones figurales }\end{array}$ & Agrupa conjuntos \\
\hline
\end{tabular}




\begin{tabular}{|c|c|c|c|c|c|c|c|c|}
\hline EC 1-20 & Preoperacional & 11 & 9 & 2.75 & BAJO & SIMPLE & $\begin{array}{l}\text { PRIMER ESTADIO } \\
\text { Colecciones figurales }\end{array}$ & Agrupa conjuntos \\
\hline EC 1-21 & Preoperacional & 14 & 6 & 3.5 & BÀSICO & SIMPLE & $\begin{array}{l}\text { PRIMER ESTADIO } \\
\text { Colecciones figurales }\end{array}$ & Agrupa conjuntos \\
\hline EC 1-22 & Preoperacional & 8 & 12 & 2 & BAJO & SIMPLE & $\begin{array}{l}\text { PRIMER ESTADIO } \\
\text { Colecciones figurales }\end{array}$ & Agrupa conjuntos \\
\hline EC 1-23 & Preoperacional & 16 & 4 & 4 & ALTO & MÚLTIPLE & $\begin{array}{l}\text { SEGUNDO ESTADIO } \\
\text { Colecciones no } \\
\text { figurales }\end{array}$ & $\begin{array}{l}\text { Establece categorías } \\
\text { conceptuales }\end{array}$ \\
\hline EC 1-24 & Preoperacional & 14 & 6 & 3.5 & BÀSICO & SIMPLE & $\begin{array}{l}\text { PRIMER ESTADIO } \\
\text { Colecciones figurales }\end{array}$ & Agrupa conjuntos \\
\hline EC 1-25 & Preoperacional & 10 & 10 & 2.5 & BAJO & SIMPLE & $\begin{array}{l}\text { PRIMER ESTADIO } \\
\text { Colecciones figurales }\end{array}$ & Agrupa conjuntos \\
\hline EC 1-26 & Preoperacional & 8 & 12 & 2 & BAJO & SIMPLE & $\begin{array}{l}\text { PRIMER ESTADIO } \\
\text { Colecciones figurales }\end{array}$ & Agrupa conjuntos \\
\hline EC 1-27 & Preoperacional & 7 & 13 & 1.75 & BAJO & SIMPLE & $\begin{array}{l}\text { PRIMER ESTADIO } \\
\text { Colecciones figurales }\end{array}$ & Agrupa conjuntos \\
\hline EC 1-28 & Preoperacional & 7 & 13 & 1.75 & BAJO & SIMPLE & $\begin{array}{l}\text { PRIMER ESTADIO } \\
\text { Colecciones figurales }\end{array}$ & Agrupa conjuntos \\
\hline EC 1-29 & Preoperacional & 12 & 8 & 3 & BÀSICO & SIMPLE & $\begin{array}{l}\text { PRIMER ESTADIO } \\
\text { Colecciones figurales }\end{array}$ & Agrupa conjuntos \\
\hline EC 1-30 & Preoperacional & 17 & 3 & 4.25 & ALTO & MÚLTIPLE & $\begin{array}{l}\text { SEGUNDO ESTADIO } \\
\text { Colecciones no } \\
\text { figurales }\end{array}$ & $\begin{array}{l}\text { Establece categorías } \\
\text { conceptuales }\end{array}$ \\
\hline EC 1-31 & Preoperacional & 9 & 11 & 2.25 & BAJO & SIMPLE & $\begin{array}{l}\text { PRIMER ESTADIO } \\
\text { Colecciones figurales }\end{array}$ & Agrupa conjuntos \\
\hline EC 1-32 & Preoperacional & 16 & 4 & 4 & ALTO & MÚLTIPLE & $\begin{array}{l}\text { SEGUNDO ESTADIO } \\
\text { Colecciones no } \\
\text { figurales }\end{array}$ & $\begin{array}{c}\text { Establece categorías } \\
\text { conceptuales }\end{array}$ \\
\hline EC 1-33 & Preoperacional & 11 & 9 & 2.75 & BAJO & SIMPLE & $\begin{array}{l}\text { PRIMER ESTADIO } \\
\text { Colecciones figurales }\end{array}$ & Agrupa conjuntos \\
\hline
\end{tabular}

Tabla 4

Consolidado de resultados de la prueba diagnóstica del curso quinto dos

\begin{tabular}{|c|c|c|c|c|c|c|c|c|}
\hline Estudiante & $\begin{array}{c}\text { ETAPADEL } \\
\text { PENSAMIENTO } \\
\text { (PIAGET) }\end{array}$ & $\begin{array}{c}\text { ACIER } \\
\text { TOS }\end{array}$ & DESACIERTOS & NOTA & $\begin{array}{c}\text { NIVELDE } \\
\text { DESEMPEÑO } \\
\end{array}$ & $\begin{array}{c}\text { TIPODE } \\
\text { CLASIFICACIÓN } \\
\text { (PIAGET) }\end{array}$ & $\begin{array}{l}\text { ESTADIO } \\
\text { (PIAGET) }\end{array}$ & $\begin{array}{l}\text { HABILIDAD DEL PENSAMIENTO } \\
\text { (MARGARITAAMESTOY DE S.) }\end{array}$ \\
\hline EC 2-1 & $\begin{array}{l}\text { Operaciones } \\
\text { concretas }\end{array}$ & 3 & 2 & 3 & BÁSICO & MÚLTIPLE & $\begin{array}{l}\text { SEGUNDO ESTADIO } \\
\text { Colecciones no figurales }\end{array}$ & Agrupa conjuntos \\
\hline EC 2-2 & $\begin{array}{l}\text { Operaciones } \\
\text { concretas }\end{array}$ & 3 & 2 & 3 & BÁSICO & MÚLTIPLE & $\begin{array}{l}\text { SEGUNDO ESTADIO } \\
\text { Colecciones no figurales }\end{array}$ & Agrupa conjuntos \\
\hline EC 2-3 & $\begin{array}{l}\text { Operaciones } \\
\text { concretas }\end{array}$ & 3 & 2 & 3 & BÁSICO & MÚLTIPLE & $\begin{array}{l}\text { SEGUNDO ESTADIO } \\
\text { Colecciones no figurales }\end{array}$ & Agrupa conjuntos \\
\hline EC $2-4$ & $\begin{array}{l}\text { Operaciones } \\
\text { concretas }\end{array}$ & 1 & 4 & 1 & BAJO & MÚLTIPLE & $\begin{array}{l}\text { SEGUNDO ESTADIO } \\
\text { Colecciones no figurales }\end{array}$ & Agrupa conjuntos \\
\hline EC 2-5 & $\begin{array}{l}\text { Operaciones } \\
\text { concretas }\end{array}$ & 0 & 5 & 1 & BAJO & MÚLTIPLE & $\begin{array}{l}\text { SEGUNDO ESTADIO } \\
\text { Colecciones no figurales }\end{array}$ & Agrupa conjuntos \\
\hline EC 2-6 & $\begin{array}{l}\text { Operaciones } \\
\text { concretas }\end{array}$ & 2 & 3 & 2 & BÁSICO & MÚLTIPLE & $\begin{array}{l}\text { SEGUNDO ESTADIO } \\
\text { Colecciones no figurales }\end{array}$ & Agrupa conjuntos \\
\hline EC 2-7 & $\begin{array}{l}\text { Operaciones } \\
\text { concretas }\end{array}$ & 0 & 5 & 1 & BAJO & MÚLTIPLE & $\begin{array}{l}\text { SEGUNDO ESTADIO } \\
\text { Colecciones no figurales }\end{array}$ & Agrupa conjuntos \\
\hline EC 2-8 & $\begin{array}{l}\text { Operaciones } \\
\text { concretas }\end{array}$ & 4 & 1 & 4 & ALTO & $\begin{array}{l}\text { INCLUSIÓN DE } \\
\text { CLASES }\end{array}$ & $\begin{array}{l}\text { TERCER ESTADIO } \\
\text { Clasificación }\end{array}$ & $\begin{array}{l}\text { Establece categorías } \\
\text { conceptuales }\end{array}$ \\
\hline
\end{tabular}




\begin{tabular}{|c|c|c|c|c|c|c|c|c|}
\hline EC 2-9 & $\begin{array}{l}\text { Operaciones } \\
\text { concretas }\end{array}$ & 0 & 5 & 1 & BAJO & MÚLTIPLE & $\begin{array}{l}\text { SEGUNDO ESTADIO } \\
\text { Colecciones no figurales }\end{array}$ & Agrupa conjuntos \\
\hline EC 2-10 & $\begin{array}{l}\text { Operaciones } \\
\text { concretas }\end{array}$ & 3 & 2 & 3 & BÁSICO & MÚLTIPLE & $\begin{array}{l}\text { SEGUNDO ESTADIO } \\
\text { Colecciones no figurales }\end{array}$ & Agrupa conjuntos \\
\hline EC 2-11 & $\begin{array}{l}\text { Operaciones } \\
\text { concretas }\end{array}$ & 4 & 1 & 4 & ALTO & $\begin{array}{l}\text { INCLUSIÓNDE } \\
\text { CLASES }\end{array}$ & $\begin{array}{l}\text { TERCER ESTADIO } \\
\text { Clasificación }\end{array}$ & $\begin{array}{l}\text { Establece categorías } \\
\text { conceptuales }\end{array}$ \\
\hline EC 2-12 & $\begin{array}{l}\text { Operaciones } \\
\text { concretas }\end{array}$ & 1 & 4 & 1 & BAJO & MÚLTIPLE & $\begin{array}{l}\text { SEGUNDO ESTADIO } \\
\text { Colecciones no figurales }\end{array}$ & Agrupa conjuntos \\
\hline EC 2-13 & $\begin{array}{l}\text { Operaciones } \\
\text { concretas }\end{array}$ & 2 & 3 & 2 & BAJO & MÚLTIPLE & $\begin{array}{l}\text { SEGUNDO ESTADIO } \\
\text { Colecciones no figurales }\end{array}$ & Agrupa conjuntos \\
\hline EC 2-14 & $\begin{array}{l}\text { Operaciones } \\
\text { concretas }\end{array}$ & 3 & 2 & 3 & BÁSICO & MÚLTIPLE & $\begin{array}{l}\text { SEGUNDO ESTADIO } \\
\text { Colecciones no figurales }\end{array}$ & Agrupa conjuntos \\
\hline EC 2-15 & $\begin{array}{l}\text { Operaciones } \\
\text { concretas }\end{array}$ & 3 & 2 & 3 & BÁSICO & MÚLTIPLE & $\begin{array}{l}\text { SEGUNDO ESTADIO } \\
\text { Colecciones no figurales }\end{array}$ & Agrupa conjuntos \\
\hline EC 2-16 & $\begin{array}{l}\text { Operaciones } \\
\text { concretas }\end{array}$ & 2 & 3 & 2 & BAJO & MÚLTIPLE & $\begin{array}{l}\text { SEGUNDO ESTADIO } \\
\text { Colecciones no figurales }\end{array}$ & Agrupa conjuntos \\
\hline EC 2-17 & $\begin{array}{l}\text { Operaciones } \\
\text { concretas }\end{array}$ & 2 & 3 & 2 & BAJO & MÚLTIPLE & $\begin{array}{l}\text { SEGUNDO ESTADIO } \\
\text { Colecciones no figurales }\end{array}$ & Agrupa conjuntos \\
\hline EC 2-18 & $\begin{array}{l}\text { Operaciones } \\
\text { concretas }\end{array}$ & 2 & 3 & 2 & BAJO & MÚLTIPLE & $\begin{array}{l}\text { SEGUNDO ESTADIO } \\
\text { Colecciones no figurales }\end{array}$ & Agrupa conjuntos \\
\hline EC 2-19 & $\begin{array}{l}\text { Operaciones } \\
\text { concretas }\end{array}$ & 1 & 4 & 1 & BAJO & MÚLTIPLE & $\begin{array}{l}\text { SEGUNDO ESTADIO } \\
\text { Colecciones no figurales }\end{array}$ & Agrupa conjuntos \\
\hline EC 2-20 & $\begin{array}{l}\text { Operaciones } \\
\text { concretas }\end{array}$ & 2 & 3 & 2 & BAJO & MÚLTIPLE & $\begin{array}{l}\text { SEGUNDO ESTADIO } \\
\text { Colecciones no figurales }\end{array}$ & Agrupa conjuntos \\
\hline EC 2-21 & $\begin{array}{l}\text { Operaciones } \\
\text { concretas }\end{array}$ & 3 & 2 & 3 & BÁSICO & MÚLTIPLE & $\begin{array}{l}\text { SEGUNDO ESTADIO } \\
\text { Colecciones no figurales }\end{array}$ & Agrupa conjuntos \\
\hline EC 2-22 & $\begin{array}{l}\text { Operaciones } \\
\text { concretas }\end{array}$ & 3 & 2 & 3 & BÁSICO & MÚLTIPLE & $\begin{array}{l}\text { SEGUNDO ESTADIO } \\
\text { Colecciones no figurales }\end{array}$ & Agrupa conjuntos \\
\hline EC 2-23 & $\begin{array}{l}\text { Operaciones } \\
\text { concretas }\end{array}$ & 3 & 2 & 3 & BÁSICO & MÚLTIPLE & $\begin{array}{l}\text { SEGUNDO ESTADIO } \\
\text { Colecciones no figurales }\end{array}$ & Agrupa conjuntos \\
\hline EC 2-24 & $\begin{array}{l}\text { Operaciones } \\
\text { concretas }\end{array}$ & 2 & 3 & 2 & BAJO & MÚLTIPLE & $\begin{array}{l}\text { SEGUNDO ESTADIO } \\
\text { Colecciones no figurales }\end{array}$ & Agrupa conjuntos \\
\hline EC 2-25 & $\begin{array}{l}\text { Operaciones } \\
\text { concretas }\end{array}$ & 2 & 3 & 2 & BAJO & MÚLTIPLE & $\begin{array}{l}\text { SEGUNDO ESTADIO } \\
\text { Colecciones no figurales }\end{array}$ & Agrupa conjuntos \\
\hline EC 2-26 & $\begin{array}{l}\text { Operaciones } \\
\text { concretas }\end{array}$ & 3 & 2 & 3 & BÁSICO & MÚLTIPLE & $\begin{array}{l}\text { SEGUNDO ESTADIO } \\
\text { Colecciones no figurales }\end{array}$ & Agrupa conjuntos \\
\hline EC 2-27 & $\begin{array}{l}\text { Operaciones } \\
\text { concretas }\end{array}$ & 3 & 2 & 3 & BÁSICO & MÚLTIPLE & $\begin{array}{l}\text { SEGUNDO ESTADIO } \\
\text { Colecciones no figurales }\end{array}$ & Agrupa conjuntos \\
\hline EC 2-28 & $\begin{array}{l}\text { Operaciones } \\
\text { concretas }\end{array}$ & 1 & 4 & 1 & BAJO & MÚLTIPLE & $\begin{array}{l}\text { SEGUNDO ESTADIO } \\
\text { Colecciones no figurales }\end{array}$ & Agrupa conjuntos \\
\hline EC 2-29 & $\begin{array}{l}\text { Operaciones } \\
\text { concretas }\end{array}$ & 2 & 3 & 2 & BAJO & MÚLTIPLE & $\begin{array}{l}\text { SEGUNDO ESTADIO } \\
\text { Colecciones no figurales }\end{array}$ & Agrupa conjuntos \\
\hline EC 2-30 & $\begin{array}{l}\text { Operaciones } \\
\text { concretas }\end{array}$ & 3 & 2 & 3 & BÁSICO & MÚLTIPLE & $\begin{array}{l}\text { SEGUNDO ESTADIO } \\
\text { Colecciones no figurales }\end{array}$ & Agrupa conjuntos \\
\hline EC 2-31 & $\begin{array}{l}\text { Operaciones } \\
\text { concretas }\end{array}$ & 3 & 2 & 3 & BÁSICO & MÚLTIPLE & $\begin{array}{l}\text { SEGUNDO ESTADIO } \\
\text { Colecciones no figurales }\end{array}$ & Agrupa conjuntos \\
\hline EC 2-32 & $\begin{array}{l}\text { Operaciones } \\
\text { concretas }\end{array}$ & 2 & 3 & 2 & BAJO & MÚLTIPLE & $\begin{array}{l}\text { SEGUNDO ESTADIO } \\
\text { Colecciones no figurales }\end{array}$ & Agrupa conjuntos \\
\hline EC 2-33 & $\begin{array}{l}\text { Operaciones } \\
\text { concretas }\end{array}$ & 3 & 2 & 3 & BÁSICO & MÚLTIPLE & $\begin{array}{l}\text { SEGUNDO ESTADIO } \\
\text { Colecciones no figurales }\end{array}$ & Agrupa conjuntos \\
\hline EC2-34 & $\begin{array}{l}\text { Operaciones } \\
\text { concretas }\end{array}$ & 2 & 3 & 2 & BAJO & MÚLTIPLE & $\begin{array}{l}\text { SEGUNDO ESTADIO } \\
\text { Colecciones no figurales }\end{array}$ & Agrupa conjuntos \\
\hline EC2-35 & $\begin{array}{l}\text { Operaciones } \\
\text { Concretas }\end{array}$ & 3 & 2 & 3 & BASICO & MÚLTIPLE & $\begin{array}{l}\text { SEGUNDO ESTADIO } \\
\text { Colecciones no figurales }\end{array}$ & Agrupa conjuntos \\
\hline
\end{tabular}


A continuación, en la figura 3, se encuentra el consolidado de resultados por porcentaje en cada curso, según los parámetros de análisis establecidos:

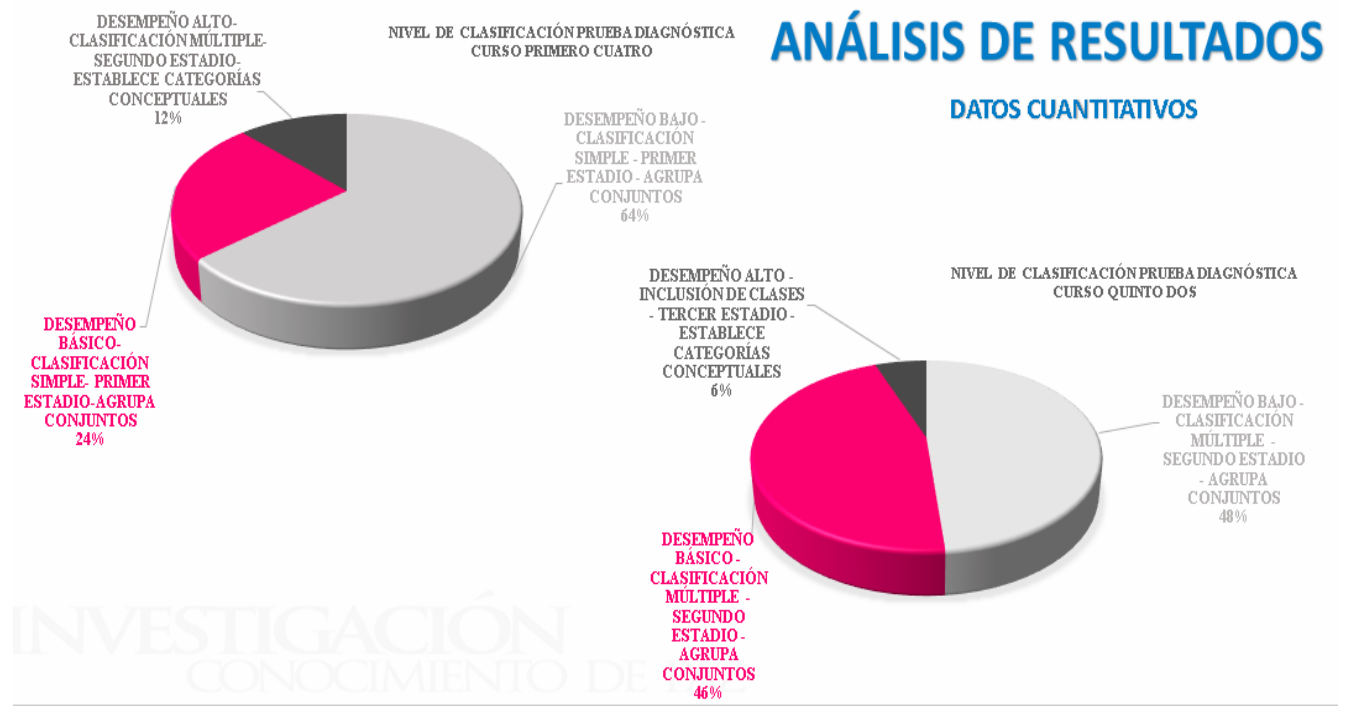

Figura 3. Consolidado de resultados por porcentaje en cada curso.

En el grado primero, según Piaget (1975), todos los estudiantes se encuentran en la etapa de pensamiento preoperacional. De los 33 estudiantes del curso primero cuatro, el $64 \%(21$ estudiantes) se encuentran en nivel de desempeño bajo, según este autor, realizan una clasificación simple porque agrupan objetos con respecto a una sola dimensión o criterio; pertenecen al primer estadio de la clasificación de colecciones figurales, puesto que organiza el material guiándose por factores figurales. Por otra parte, según Margarita Amestoy de Sánchez, realiza una operación mental que consiste en agrupar conjuntos de personas, objetos, eventos o situaciones en categorías denominadas clases.

E1 $24 \%$ (8 estudiantes) de los estudiantes se encuentran en nivel de desempeño básico, con los mismos elementos de análisis según Piaget y Amestoy. El 12 $\%$ (4 estudiantes), se encuentra en nivel de desempeño alto, correspondiente a la clasificación múltiple, donde clasifica objetos simultáneamente con respecto a dos o más dimensiones o criterios; se encuentra en el segundo estadio colecciones no figurales, clasificando los objetos con pocos errores y así realiza una clasificación con respecto a un solo criterio. Por otro lado, según Amestoy de Sánchez, cumple la operación mental que consiste en establecer categorías conceptuales, esto es, denominaciones abstractas que se refieren a un número limitado de características de las personas, objetos, eventos o situaciones y no a las personas, objetos, eventos o situaciones directamente. 
En el curso quinto, según Piaget (1975), todos los estudiantes se encuentran en la etapa de pensamiento operaciones concretas. De los 35 estudiantes del curso 5-2, el $48 \%$ (17 estudiantes) se encuentran en nivel de desempeño bajo, según Piaget realizan una clasificación simple porque agrupan objetos con respecto a una sola dimensión o criterio; pertenecen al primer estadio de la clasificación de colecciones figurales, pues organiza el material guiándose por factores figurales. Por otra parte, según Amestoy de Sánchez, realiza una operación mental que consiste en agrupar conjuntos de personas, objetos, eventos o situaciones en categorías denominadas clases. El $46 \%$ (16 estudiantes), se encuentran en nivel de desempeño básico, con los mismos elementos de análisis según Piaget y Amestoy.

El $6 \%$ (2 estudiantes) se encuentra en nivel de desempeño alto, correspondiente a la clasificación múltiple, donde clasifica objetos simultáneamente con respecto a dos o más dimensiones o criterios; se encuentra en el segundo estadio colecciones no figurales, clasificando los objetos con pocos errores y así realiza una clasificación con respecto a un solo criterio. Por otro lado, según Amestoy de Sánchez, cumple la operación mental que consiste en establecer categorías conceptuales, esto es, denominaciones abstractas que se refieren a un número limitado de características de las personas, objetos, eventos o situaciones y no a las personas, objetos, eventos o situaciones directamente.

Fase III. Propuesta ¡Clasificando ando $\mathrm{y}$ animales investigando!

Por último y teniendo en cuenta los resultados de la prueba diagnóstica, está la propuesta ¡Clasificando ando y animales investigando!, la cual consta del diseño, ejecución y evaluación de siete talleres, "El taller como alternativa de renovación pedagógica" (Ander Egg, 1999), con un formato innovador donde el estudiante conoce extraños animales que existen en la naturaleza; los agrupa según características específicas; organiza información en un esquema gráfico; investiga un animal de cada grupo específico de animales y socializa con sus compañeros. Al final de cada taller y como producto de investigación, el educando toma fotografías donde está él con la familia junto a animales de la región, de acuerdo con la temática referida en cada clasificación, decora el animal predilecto con técnicas artísticas y entrega su álbum fotográfico; y el último taller consta de un software lúdico aplicando las TIC y fortaleciendo así el proceso de enseñanza-aprendizaje.

Las figuras 4 y 5 , muestran el diseño de los talleres de los cursos primero y quinto, respectivamente.
En el curso quinto, según Piaget (1975), todos los estudiantes se encuentran en la etapa de pensamiento operaciones concretas. 


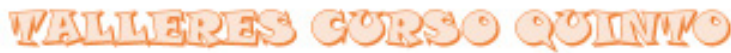
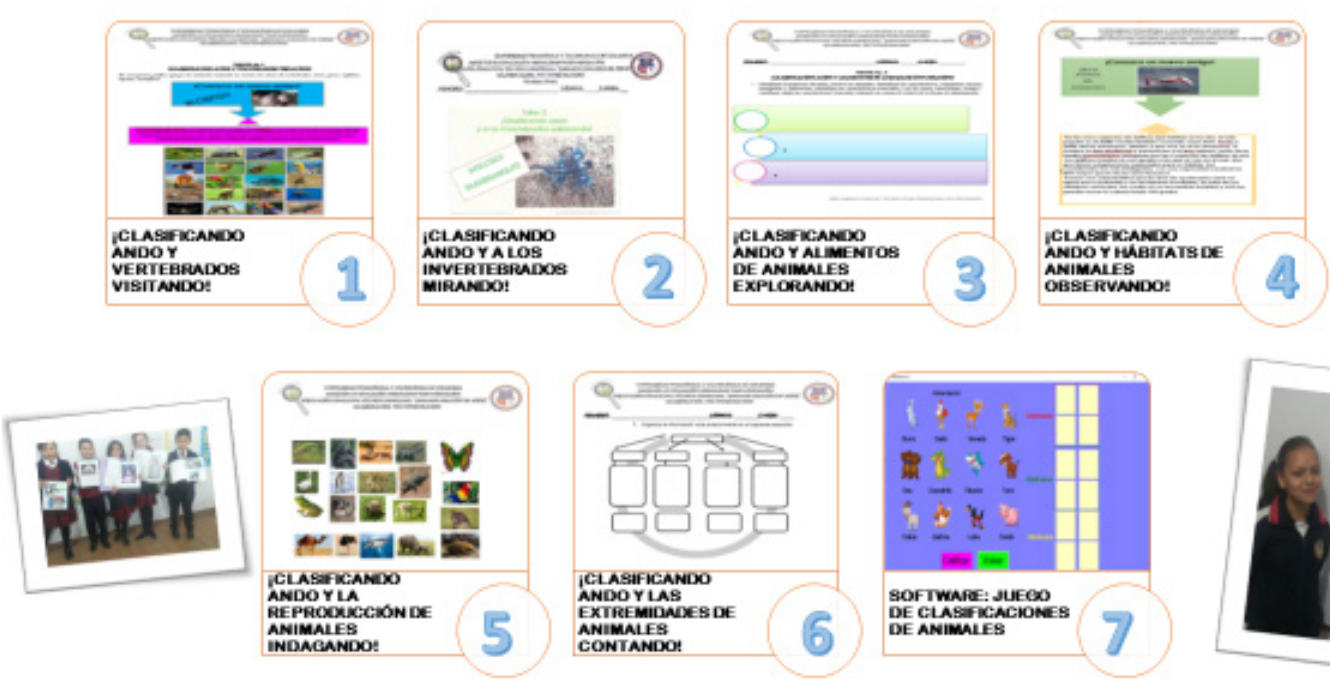

Figura 4. Diseño de los talleres del curso primero.

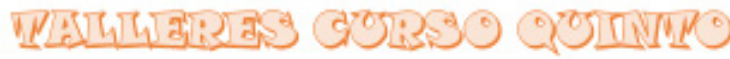

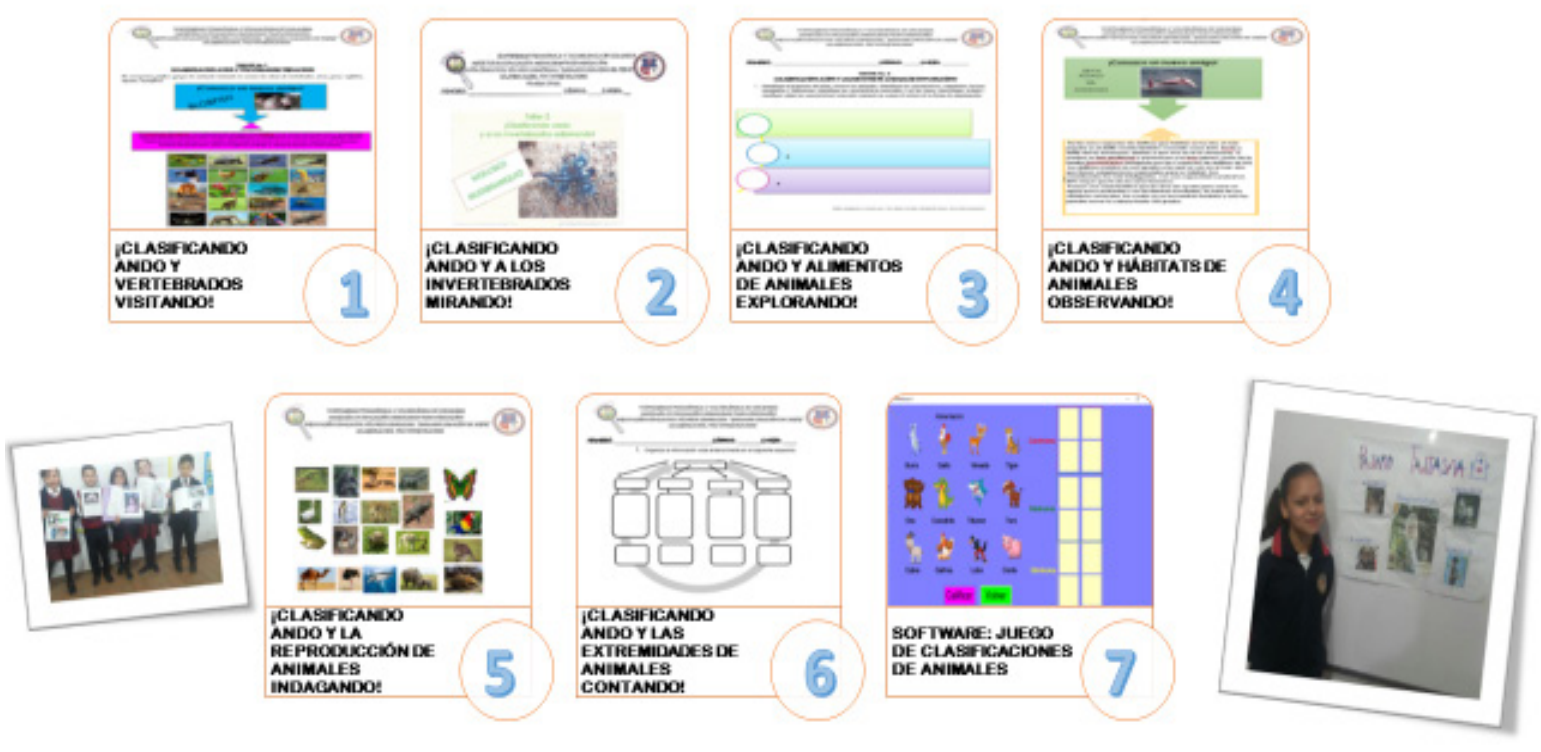

Figura 5. Diseño de los talleres de curso quinto. 
Cada taller es evaluado por el grupo de investigación teniendo en cuenta el estudio de la clasificación que realiza Piaget (1975) dentro del desarrollo del pensamiento; a Amestoy de Sánchez (1995), quien analiza la clasificación como habilidad del pensamiento; Fonseca (s.f.) y su aporte a la competencia investigativa; y Ander Egg (1999), con el uso del taller como renovación pedagógica. De este modo, en la figura 6 se muestra la matriz de evaluación elaborada por el equipo investigador con los criterios de evaluación correspondientes.

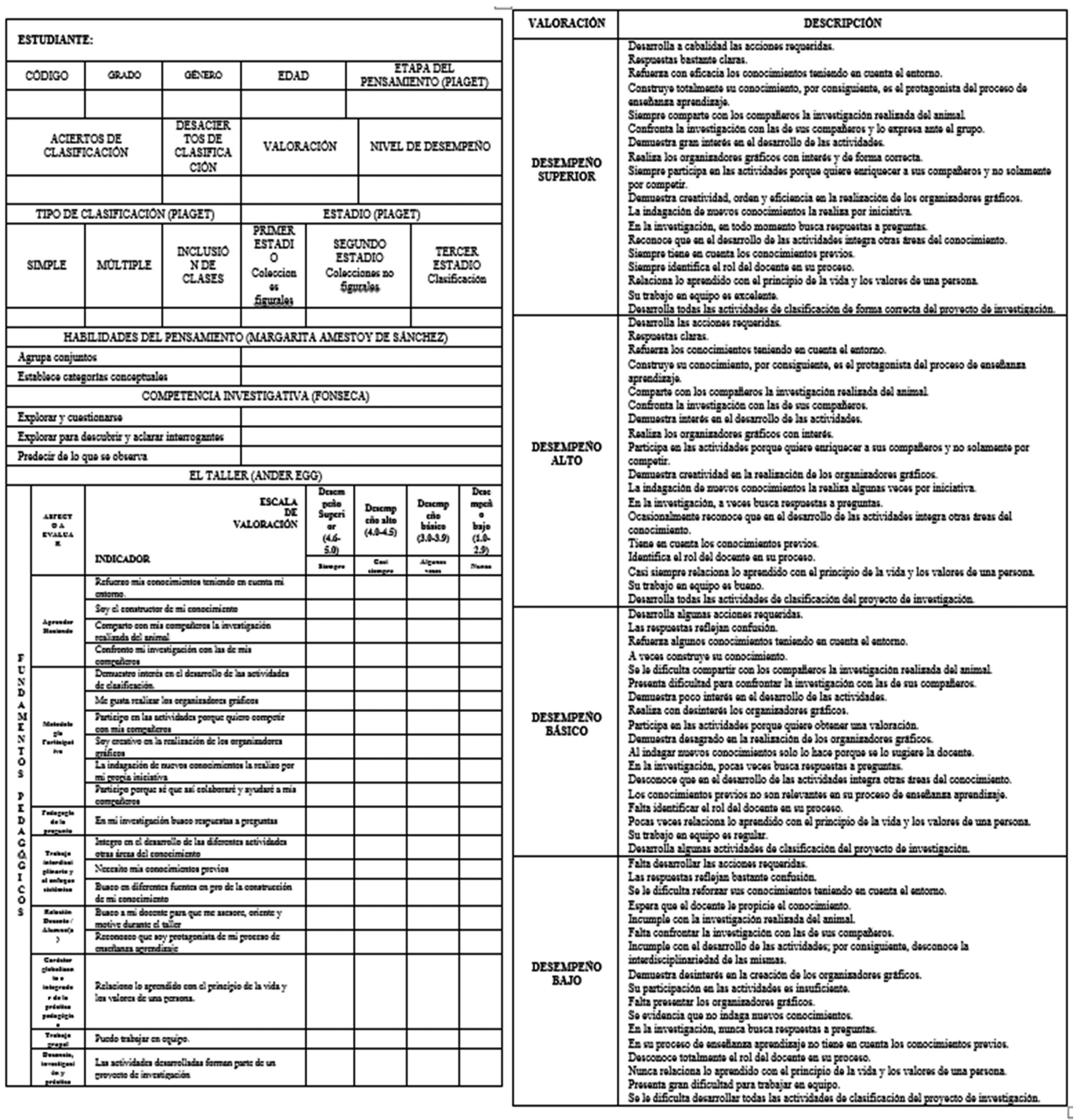

Figura 6. Matriz y criterios de evaluación para los talleres. 
Teniendo en cuenta el nivel de desempeño de los talleres, la figura 7 muestra el avance de los estudiantes.

\section{RESULTADOS}

TALLERES

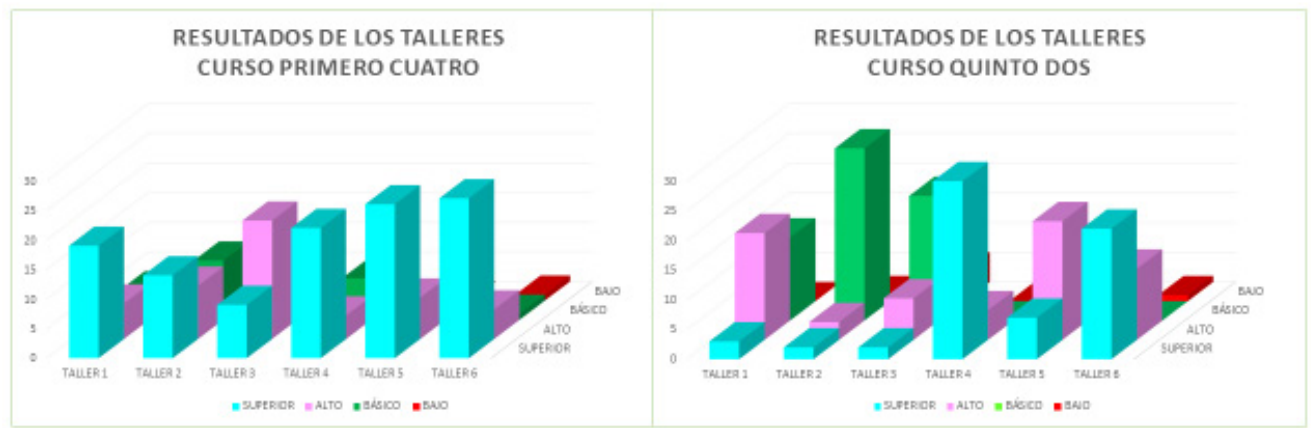

Figura 7. Nivel de desempeño de cada uno de los talleres.

Cada taller refleja resultados de acuerdo con los saberes previos, los aprendizajes de la experiencia y los intereses de los estudiantes por determinada clasificación de animales.

Así, en el curso primero, los talleres muestran un alto nivel de progreso en orden descendente: el 6 (animales salvajes y domésticos), el 5 (clasificación de animales según la reproducción), el 4 (animales vertebrados e invertebrados). Mientras que, en el curso quinto, los talleres con mejores resultados en su orden, fueron: el 4 (clasificación de animales según el hábitat), el 6 (clasificación de animales según las extremidades), y el 5 (clasificación de animales según su reproducción).
Por otra parte, a nivel de la clasificación como habilidad de pensamiento, en la figura 8 , se presenta la gráfica del avance de los estudiantes según el curso respectivo.

En el curso primero, según Piaget (1975), todos los estudiantes se encuentran en la Etapa de pensamiento preoperacional. Se evidencia porcentaje sobresaliente de nivel de desempeño alto y superior, correspondiente a la clasificación múltiple (segundo estadio colecciones no figurales). Por otro lado, conforme a Amestoy de Sánchez, cumple la operación mental que consiste en establecer categorías conceptuales. 


\section{PRUEBA FINAL}
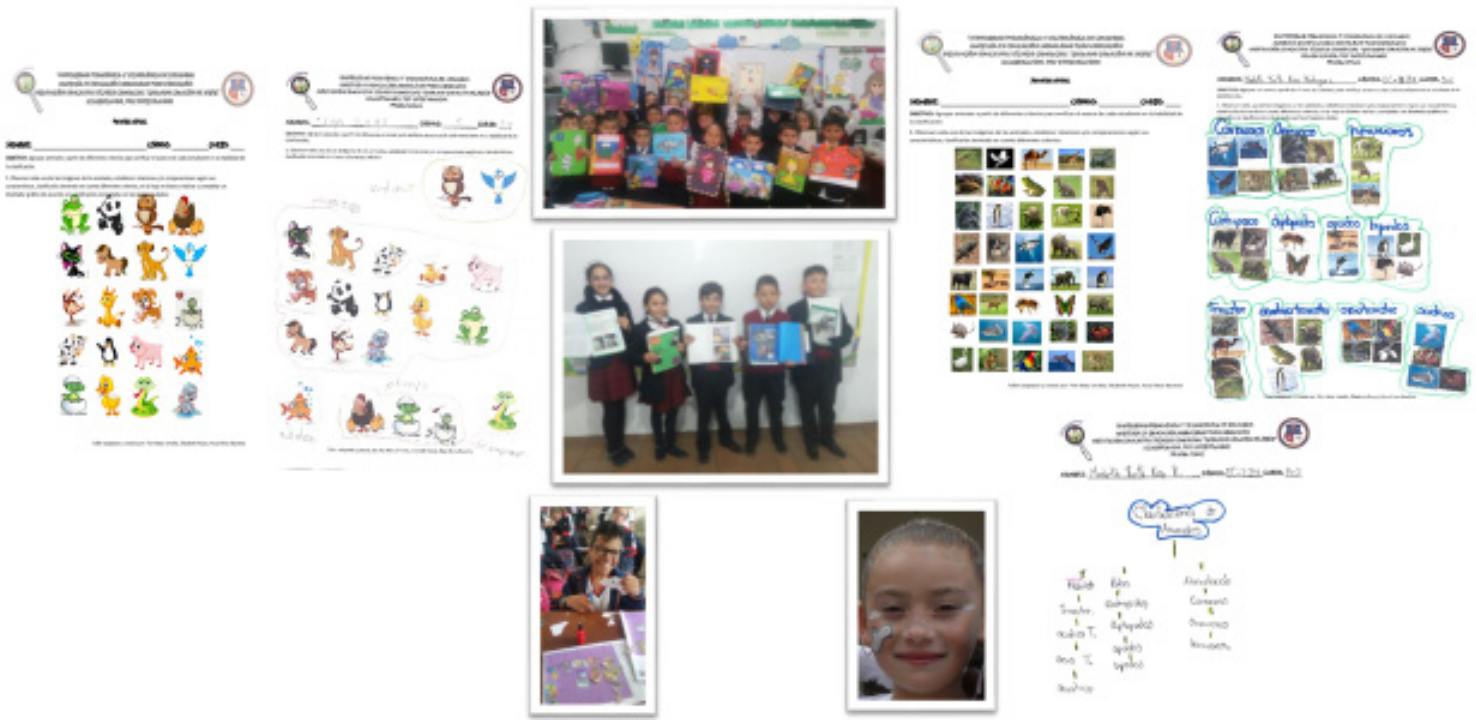

La Figura 9 presenta el diseño, muestra y evidencia de la prueba final.

Figura 8. Nivel de clasificación de cada uno de los talleres.

En el curso quinto, según Piaget (1975), todos los estudiantes se encuentran en la Etapa de pensamiento operaciones concretas. El mayor porcentaje de estudiantes se encuentra en nivel de desempeño alto y superior, correspondiente a la clasificación múltiple (segundo estadio colecciones no figurales). Alcanzan el tercer estadio de la inclusión de clases. Según Amestoy de Sánchez, cumple la operación mental que consiste en establecer categorías conceptuales.

\section{Resultados}

Para analizar y reflexionar acerca del avance real de los estudiantes en el nivel de clasificación como habilidad del pensamiento, se diseña y ejecuta la prueba final. Esta incluye una hoja en blanco y varias imágenes de animales, y consiste en que cada estudiante realice la mayor parte de clasificaciones de animales en forma libre. En el curso quinto, luego, elaborar un organizador gráfico que reúna todo el contenido del trabajo que hizo.

Así, conforme a Lafourcade (citado en Ruiz, 2014), la evaluación tiene como fin comprobar, de forma sistemática, la medida en que se han obtenido los objetivos de aprendizaje propuestos. De ahí la importancia de comparar los resultados de la prueba diagnóstica con la final y poder evidenciar los avances del nivel de clasificación. 


\section{¡NIVEL DE CLASIFICACIÓN PRUEBA FINAL!}
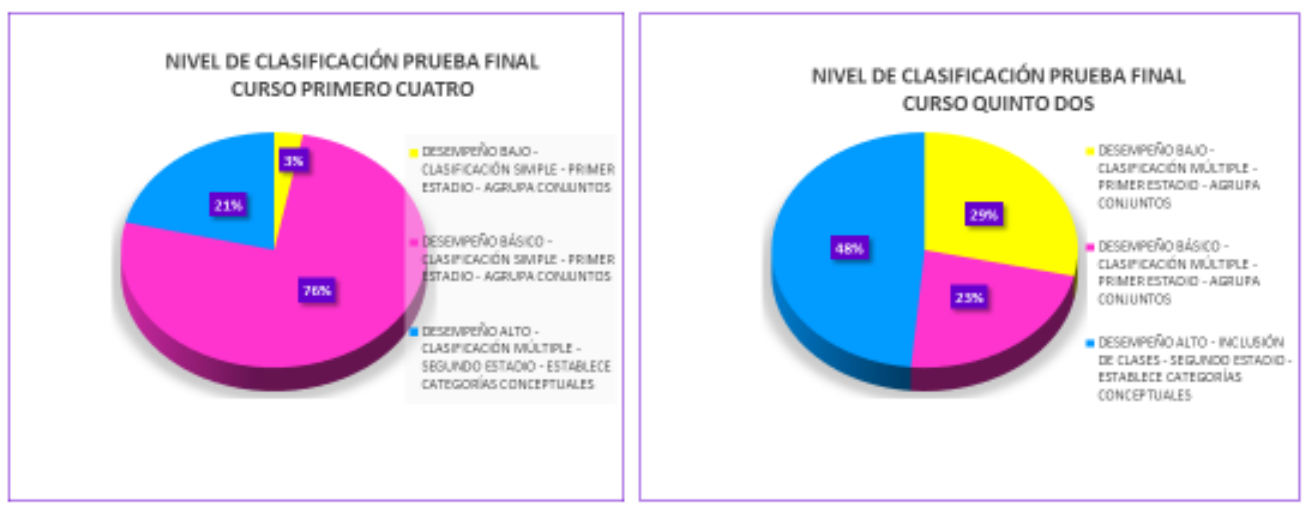

Figura 9. Diseño, muestra y evidencia de la prueba final.

En la figura 10, se presentan los resultados de la evaluación final realizada con el fin de realizar la comparación con la prueba diagnóstica para una reflexión integral del aporte de la propuesta.

Figura 10. Resultados de la evaluación final.

En el curso primero, según Piaget (1975), todos los estudiantes se encuentran en la etapa de pensamiento preoperacioanal.

De los 33 estudiantes del curso primero cuatro, el $3 \%$ (1 estudiante) está en el nivel de desempeño bajo, clasificación simple, primer estadio de la clasificación de colecciones figurales. Como lo señala Amestoy (1995), agrupa conjuntos en categorías denominadas clases.
El $76 \%$ (25 estudiantes), en el nivel de desempeño básico, clasificación simple, primer estadio de la clasificación de colecciones figurales. Según Amestoy (1995), agrupa conjuntos en categorías denominadas clases.

El $21 \%$ (7 estudiantes), en el nivel de desempeño alto, la clasificación múltiple, segundo estadio colecciones no figurales. Según Amestoy de Sánchez, agrupa conjuntos teniendo en cuenta características.

En el curso quinto, todos los estudiantes se encuentran en la etapa de pensamiento operaciones concretas, siguiendo a Piaget (1975).

De los 35 estudiantes del curso quinto dos, el $29 \%$ (10 estudiantes) está en el nivel de desempeño bajo, clasificación múltiple, segundo estadio de la clasificación de colecciones 
no figurales. Según Amestoy (1995), agrupa conjuntos de en categorías denominadas clases.

El $23 \%$ (8 estudiantes), en el nivel de desempeño básico, con los mismos elementos de análisis según Piaget y Amestoy.

El $48 \%$ (17 estudiantes), en el nivel de desempeño alto. Alcanzan el tercer estadio de la inclusión de clases. Por otro lado, según Amestoy de Sánchez, cumple la operación mental que consiste en establecer categorías conceptuales.

Finalmente, se realiza la comparación entre la prueba diagnóstica con la final, en espera de un incremento en la clasificación como habilidad del pensamiento como aporte significativo en el aprendizaje de los estudiantes. Además, alcanzar una aproximación a la sensibilización de los estudiantes, respecto al gusto por la investigación como medio para construir saberes.

De esta forma, la figura 11 presenta el análisis comparativo de cada curso.

Figura 11. Análisis comparativo entre la prueba diagnóstica y la prueba final de cada curso.

En el curso primero, según Piaget (1975), todos los estudiantes se encuentran en la etapa de pensamiento preoperacioanal.

En el nivel de desempeño bajo, descendió el número de estudiantes, de $64 \%$ a $3 \%$, dando evidencias de un 61 $\%$ de mejoramiento en la clasificación, pasando de la simple a la múltiple, del primer estadio de la clasificación de colecciones figurales al segundo de no figurales (Piaget, 1975). Según Amestoy (1995), pasan de agrupar conjuntos en categorías denominadas clases, a establecer categorías conceptuales.

El desempeño básico aumentó de 24 $\%$ a $76 \%$, dando paso un $52 \%$ de estudiantes que superaron dificultades dentro del nivel bajo.

El desempeño alto ascendió, de $12 \%$ a $21 \%$, con un mejoramiento de $9 \%$ de la clasificación múltiple, segundo estadio colecciones no figurales. Según Amestoy (1995), establece categorías conceptuales.

Desde la perspectiva de Amestoy de Sánchez, logran el paso de agrupación de conjuntos por características comunes a establecer categorías.

En el curso quinto, según Piaget (1975), todos los estudiantes se encuentran en la etapa de pensamiento operaciones concretas.

Dentro del nivel de desempeño bajo, el porcentaje de estudiante bajó de $48 \%$ a $29 \%$, es decir, hubo un 19 $\%$ de superación de dificultades. Teniendo en cuenta a Piaget (1975), la clasificación múltiple, segundo estadio de la clasificación de colecciones no figurales. Según Amestoy (1995), agrupa conjuntos en categorías denominadas clases.

En el nivel de desempeño básico, desciende el número de estudiantes, de $46 \%$ al $23 \%$, dando paso al 23 $\%$ de mejoramiento del grado de 
clasificación, de acuerdo con las pautas teóricas de Piaget (1975) y Amestoy (1995), respecto al proceso de la clasificación.

Seguidamente, el nivel de desempeño alto sube notablemente del $6 \%$ al 48 $\%$, con un número significativo de estudiantes representado en el $42 \%$ que alcanzan la inclusión de clases (Piaget, 1975), tercer estadio clasificación.
Desde Amestoy (1995), establece categorías conceptuales.

Desde la perspectiva de Amestoy de Sánchez, logran el paso de agrupación de conjuntos por características comunes a establecer categorías.

A partir de lo anterior, el porcentaje de aporte en el nivel de la clasificación, se presenta en la figura 12.

\section{CURSO PRIMERO 4}

\section{CURSO QUINTO 2}

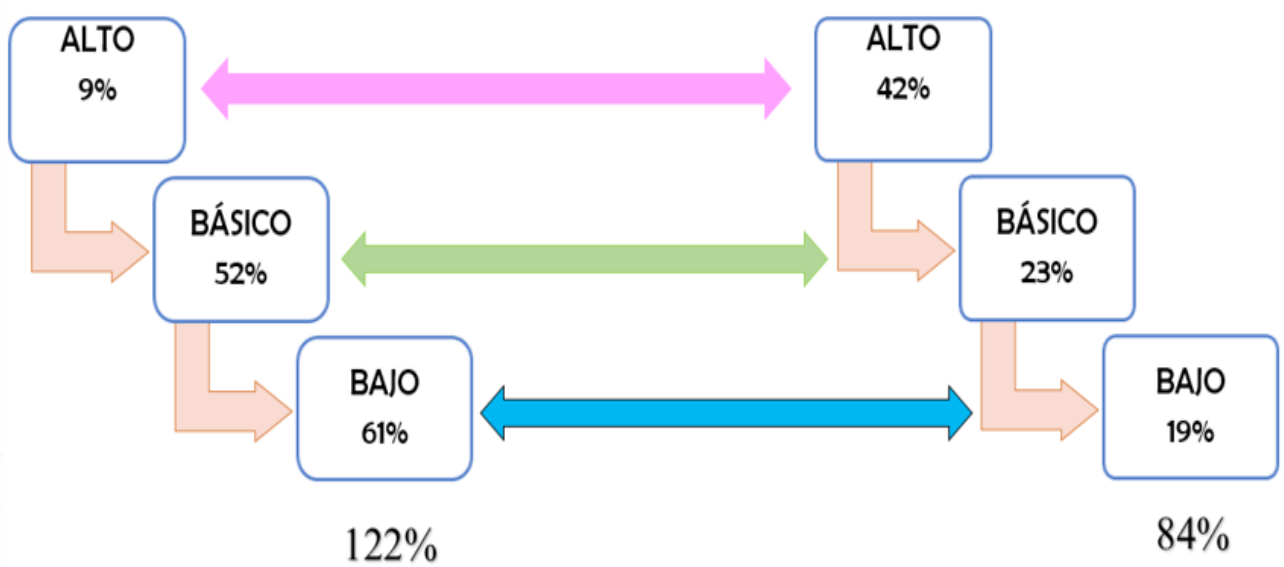

Figura 12. Porcentaje de comparación entre los dos cursos respecto a la prueba diagnóstica y la final.

La figura permite evidenciar que los estudiantes de curso primero alcanzan un nivel de eficiencia en el nivel de clasificación de $38 \%$ más que el curso quinto, de acuerdo con la etapa de pensamiento preoperacional en que se encuentran según Piaget (1975); pero es de aclarar que, el nivel de aprendizaje del curso quinto es más amplio de acuerdo con el manejo temático que alcanzan y, por supuesto, a la etapa de pensamiento de operaciones concretas.

\section{Conclusiones}

Las habilidades del pensamiento son fundamentales para el proceso de aprendizaje, porque permiten al ser humano el desarrollo de un razonamiento lógico, crítico y creativo, 
y para resolver problemas. Así, se convierten en ejes fundamentales para el docente tomando fines didácticos para el quehacer pedagógico. De ahí, la importancia del diagnóstico donde se logra direccionar la ruta de investigación a partir de la prueba, para detectar el nivel de la habilidad de la clasificación en el pensamiento de los estudiantes de nivel primero y quinto de educación básica primaria. Esta etapa inicial permite no solo la comparación entre los resultados de los dos niveles, sino que da paso a la reflexión en la búsqueda de una propuesta de aporte al mejoramiento de este proceso mental.

La clasificación es una de las operaciones lógicas elementales y uno de los primeros sistemas operatorios importantes en el pensamiento del estudiante, por lo cual es trascendental el fortalecimiento mediante estrategias innovadoras y efectivas para tal fin. Por lo tanto, el análisis de resultados evidencia que los estudiantes de nivel inicial tienen más facilidad para la elaboración de preguntas durante la prueba, que los estudiantes de curso quinto; y por lo tanto, el nivel de clasificación, aunque es simple según Piaget (1975) por la etapa de pensamiento operacional en que se encuentran, presenta un manejo más efectivo en la formación de grupos con características comunes, teniendo en cuenta la clasificación como habilidad del pensamiento (Amestoy, 1995).

La intervención del equipo de investigación conlleva al diseño de una propuesta que incluye la estrategia metodológica del taller, como alternativa de renovación pedagógica de Ander Egg (1999), para fortalecer la clasificación como habilidad del pensamiento, y a la vez reafirmar la competencia investigativa, buscando la adquisición de conocimientos, habilidades, actitudes y valores necesarios para investigar; de esta forma, en esta fase se concluye que en los estudiantes de primaria es pertinente promover una aproximación a partir del contexto, y en este caso el encuentro con animales de la región reafirma el gusto por la indagación de temas de la naturaleza, y evidencia una experiencia significativa, en familia, en contacto con la naturaleza y con el saber a través del registro fotográfico y el arte, dentro de un escenario de aprendizaje interdisciplinario.

La interdisciplinariedad de áreas del saber proporciona una gran riqueza en cuanto a las posibilidades que le brinda al estudiante para el aprendizaje, ya que le permite abordar saberes desde varios puntos de vista. En este caso, fortalece la habilidad de la clasificación con la temática de los animales que hace parte de ciencias naturales; el arte en diversas creaciones; español en la redacción textual y en exposiciones orales; ética y valores, en el trabajo en equipo con la familia para el registro fotográfico; y la indagación como aproximación a la investigación para llegar a realizar conclusiones razonadas. De esta forma, el estudiante logra, a partir de una disciplina concreta, desde su lógica interna, desde sus contenidos construidos con ciertos métodos y propósitos, dar paso a la interdisciplinariedad del saber. 
Finalmente, en la comparación entre la prueba diagnóstica con la evaluación final, los resultados de avance de los estudiantes, tanto en curso primero como de quinto, reafirman el logro de metas de progreso en el aprendizaje de la temática de clasificación de animales del área de ciencias naturales; fortalecen la habilidad para el proceso de clasificación; manifiestan motivación hacia nuevas experiencias de indagación en el contexto natural; valoran los nuevos aprendizajes con estrategias creativas; reflexionan acerca de la importancia del compartir en familia; ven en la fotografía un medio de aprendizaje; disfrutan de la expresión artística; y además, hacen el proceso de reflexión para dar comentarios positivos de esta experiencia.

\section{Referencias}

Amaya, B. (2003). Influencia del uso de mapas conceptuales en la construcción de la babilidad clasificación en ciencias naturales. (Tesis de maestría). Universidad de Manizales, Caldas, Colombia.

Amestoy, M. (1995). Desarrollo de habilidades del pensamiento. Procesos básicos del pensamiento. México: Trillas.

Ander Egg, E. (1999). El taller una alternativa de renovación pedagógica. Recuperado de https://uacmtalleresliterarios.files.wordpress.com/2011/02/ el-taller-como-sistema-de-ensec3b1anza-aprendizaje.pdf

Fonseca, G. (s.f.). La implementación del enfoque didáctico de investigación dirigida y el desarrollo de competencias científicas en un grupo de educación básica. Sistematización de una experiencia de acompañamiento docente. Recuperado de http://academicos.iems.edu.mx/cired/docs/ $\mathrm{tg} /$ macroacademiaquimica/Formacion $\% 20 \mathrm{y} \% 20$ evaluacion $\% 20 \mathrm{de} \% 20$ competencias\%20cinetificas_FonsecaAmaya.pdf

Institución Técnico Comercial Sagrado Corazón de Jesús (2015). Plan de Mejoramiento Institucional PMI. Chiquinquirá. Colombia.

Institución Técnico Comercial Sagrado Corazón de Jesús (2014). Proyecto Educativo Institucional PEI. Chiquinquirá. Colombia.

Institución Técnico Comercial Sagrado Corazón de Jesús (2015). Sistema Institucional de Evaluación de Estudiantes SIEE. Chiquinquirá. Colombia.

Martínez, V. (2013). Paradigmas de investigación. Manual multimedia para el desarrollo de trabajos de investigación. Una visión desde la epistemología dialéctico crítica. Recuperado de http:/www.pics.uson.mx/wp-content/ uploads/2013/10/7_Paradigmas_de_investigacion_2013.pdf 
Martínez, D., \& Márquez, D. (2014). Las habilidades Investigativas como eje transversal de la formación para la investigación. Revista tendencias pedagógicas.

Ministerio de Educación Nacional. (2012) MEN. Colombia en Pisa 2012. Principales resultados. Bogotá, diciembre 3 de 2013.

Ministerio de Educación Nacional. (2016) MEN. Informe nacional de resultados Saber Pro 2012 - 2015.

Murillo, F. (2010). Investigación Acción. Recuperado de https://www.uam.es/ personal_pdi/stmaria/jmurillo/InvestigacionEE/Presentaciones/Curso_10/ Inv_accion_trabajo.pdf

Pereira, P. (2011). Los diseños de método mixto en la investigación en educación: Una experiencia concreta. Revista Electrónica Educare, XV(1), 15-29.

Piaget, J. (1975). La equilibración de las estructuras cognitivas. Problema central del desarrollo. Madrid: Siglo XXI.

Restrepo, F. (2007). Habilidades investigativas en niños y niñas de 5 a 7 años de instituciones oficiales y privadas de la ciudad de Manizales. (Tesis de doctorado). Universidad de Manizales, Caldas, Colombia. 